\title{
Stereospecific Anionic Polymerization and Novel Hydrogen-Transfer Polymerization of $\alpha$-(Aminomethyl)acrylates Having Unprotected Amino Group
}

\author{
Hideo Baraki, Shigeki Habaue, and Yoshio OKamoto ${ }^{\dagger}$ \\ Department of Applied Chemistry, Graduate School of Engineering, \\ Nagoya University, Furo-cho, Chikusa-ku, Nagoya 464-8603, Japan
}

(Received May 27, 1999)

\begin{abstract}
Anionic polymerization of $\alpha$-(aminomethyl)acrylates $(\mathbf{2}-\mathbf{8})$ having an unprotected amino proton was carried out using lithium reagents at $-78^{\circ} \mathrm{C}$. Acrylates except for $\mathbf{4}$ and $\mathbf{8}$ afforded the polymers in good yields. The polymerization of ethyl $\alpha$-[N-(diphenylmethyl)aminomethyl]acrylate (3) with $n$-BuLi or the $\mathrm{Ph}_{2} \mathrm{NLi}-N, N, N^{\prime}, N^{\prime}$-tetramethylethylenediamine (TMEDA) complex in toluene afforded a polymer with a normal vinyl polymer structure and high isotacticity. Hydrogentransfer of the amino proton hardly occurred in the polymerization process. The anionic polymerizations of ethyl $\alpha-[N$-(1-phenylethyl)aminomethyl $]$ acrylate (2) using lithium reagents in toluene and tetrahydrofuran (THF) proceeded with hydrogen-transfer reaction. CH carbon generated by hydrogen-transfer in the main chain was detected by DEPT NMR measurement of poly(2). The $\mathrm{CH}$-containing unit in the polymer increased up to nearly $40 \%$ when THF was used as a solvent. Monomers 4 and 8 showed low polymerizability.

KEY WORDS Anionic Polymerization / Hydrogen-Transfer Polymerization / Stereospecific Polymerization / $\alpha$-(Aminomethyl)acrylate / Lithium Amide / Isotactic Polymer / Optically Active Polymer /
\end{abstract}

Control of stereochemistry in the polymerization of vinyl monomers is an important area in synthetic polymer chemistry. In anionic polymerization, tacticity of polymers is often greatly affected by polymerization conditions such as polarity of solvents and initiators. Therefore, the introduction of a polar functional group to a vinyl monomer that interacts with a countercation may greatly influence the stereoregulation of polymerization. A large number of $\alpha$-substituted acrylates usually yields atactic or syndiotactic polymers through radical polymerization. ${ }^{1}$ Recently, we found that the anionic polymerization of $\alpha$-(alkoxymethyl)acrylates and $\alpha-(N, N$ dialkylaminomethyl)acrylates with lithium reagents gave highly isotactic polymers regardless of the polarity of solvents. ${ }^{2,3}$ The main factor in controlling the stereochemistry of the polymerization should be the strong intra- and intermolecular coordination power of the polar groups of a growing polymer chain end and monomers to the countercation $\left(\mathrm{Li}^{+}\right)$. Stereospecific synthesis of the polymers possessing a variety of polar groups is particularly important for generating novel functional polymers. We reported that the anionic polymerization of ethyl $\alpha$-( $N$ - $t$-butylaminomethyl)acrylate (1) having a reactive unprotected amino group with the lithium amide complexes such as the lithium diphenylamide complex with $N, N, N^{\prime}, N^{\prime}$-tetramethylethylenediamine $\left(\mathrm{Ph}_{2} \mathrm{NLi}\right.$ TMEDA) in toluene afforded an isotactic polymer, while the polymerization in tetrahydrofuran (THF) gave a syndiotactic polymer. ${ }^{4}$ The tacticity of the obtained polymer was fairly affected by the polarity of solvents and initiators. These results are quite different from those of the previously reported monomers, which have a polar substituent on the $\alpha$-position of an acrylate. ${ }^{2,3}$ The hydrogen-transfer polymerization ${ }^{5-10}(\mathrm{H}$-transfer polymerization) on the active amino proton did not occur in this system. The stereoregular polymer having a reactive amino proton in the side chain is attractive as a reactive

$\dagger$ To whom all correspondence should be addressed. polymer, polymeric base, or ligand.

Reported herein is the anionic polymerization of novel $\alpha$-(aminomethyl)acrylates having various aminomethyl groups at the $\alpha$-position, ethyl $\alpha-[N-(1-$ phenylethyl)aminomethyl $]$ acrylate (2), ethyl $\alpha$-[N-(diphenylmethyl)aminomethyl $]$ acrylate (3), ethyl $\alpha$-[N-(triphenylmethyl)aminomethyl] acrylate (4), ethyl $\alpha$-(anilinomethyl)acrylate (5), ethyl $\alpha$-[(3,5-dimethylanilino)methyl]acrylate (6), ethyl $\alpha-[(3,5$-dimethoxyanilino)methyl $]$ acrylate (7), and ethyl $\alpha-[(3,5-$ dichloroanilino)methyl $]$ acrylate (8). The generality of the stereospecific polymerization of acrylates bearing a reactive amino group at the $\alpha$-position and effects of various amino groups on the reactivity in the anionic polymerization are examined.

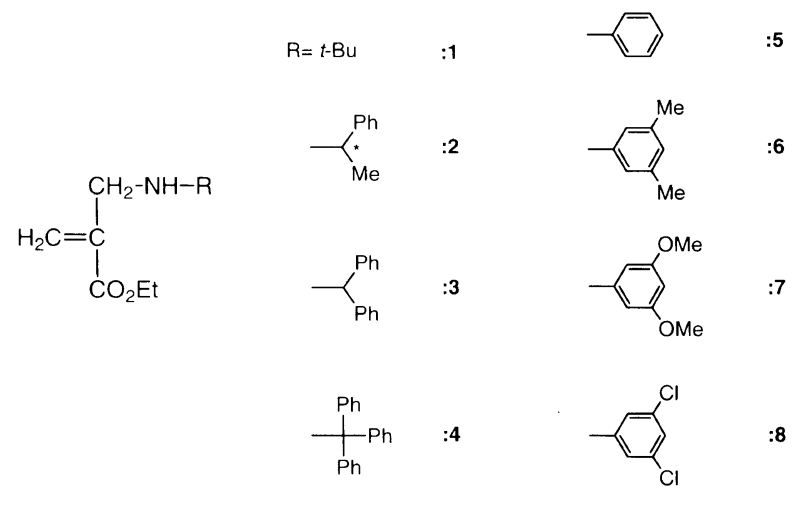

EXPERIMENTAL

\section{Measurements}

${ }^{1} \mathrm{H}$ and ${ }^{13} \mathrm{C}$ NMR spectra were measured on a Varian Unity-Inova $\left(500 \mathrm{MHz}\right.$ for $\left.{ }^{1} \mathrm{H}\right)$ and a Gemini-2000 ( $400 \mathrm{MHz}$ for ${ }^{1} \mathrm{H}$ ) spectrometers in $\mathrm{CDCl}_{3}$. Chemical shifts are reported in part per million (ppm) with tetramethylsilane (TMS, $0 \mathrm{ppm}$ ) and $\mathrm{CDCl}_{3}(77.0 \mathrm{ppm})$ as an internal standard for ${ }^{1} \mathrm{H}$ and ${ }^{13} \mathrm{C}$ NMR, respectively. Infrared (IR) spectra were recorded on a JACSO FT/IR-620 spectrometer. Circular dichroism 
(CD) spectra were taken on a JASCO J-720L. UV spectra were measured on a JASCO Ubest-55 spectrophotomerter. Optical rotation was measured with a JASCO DIP-181 polarimeter. Size exclusion chromatography (SEC) analysis of obtained polymers was unsuccessful probably because of strong interactions between a polystyrene-based gel and amine containing polymers. The number-average molecular weight $\left(M_{n}\right)$ of the obtained polymers was determined with a vapor pressure osmometer (VPO, Gonotec Osmomat 070) using $\mathrm{CHCl}_{3}$ as solvent. The chromatographic resolution of racemic 2 was performed on a JASCO PU980 chromatograph equipped with a UV detector (JASCO UV970) and polarimetric detector (JASCO ORD-990) using a chiral column, CHIRALCEL OD (Daicel).

\section{Materials}

Toluene and THF used in polymerization were distilled from $\mathrm{Na}$ wire and distilled again from $n$-butyllithium $(n-\mathrm{BuLi})$ for toluene and $\mathrm{LiAlH}_{4}$ for THF under high vacuum just before use. $n$-BuLi was prepared from 1-chlorobutane and lithium powder in heptane under an atmosphere of argon. Lithium amides, $\mathrm{Ph}_{2} \mathrm{NLi}$ and $N, N^{\prime}$-diphenylethylenediamine monolithium amide (DPEDALi), as initiators were prepared from the corresponding secondary amine by adding an equimolar amount of $n$-BuLi at room temperature. Lithium amide complexes with diamines [TMEDA and (-)-sparteine $((-) \mathrm{Sp})]$ were prepared by mixing lithium reagent with 1.2 equiv. of diamine at room temperature under dry nitrogen.

\section{Synthesis of $\alpha$-(Aminomethyl)acrylates}

Ethyl $\alpha-[N-(1-$ Phenylethyl)aminomethyl $]$ acrylate (2). To a mixture of racemic 1 -phenylethylamine $(2.8 \mathrm{~g}$, $23.2 \mathrm{mmol})$ and triethylamine $(2.4 \mathrm{~g}, 23.7 \mathrm{mmol})$ in dichloromethane $(30 \mathrm{~mL})$ was added dropwise a solution of ethyl $\alpha$-(bromomethyl)acrylate ${ }^{11}(4.4 \mathrm{~g}, 22.8 \mathrm{mmol})$ in dichloromethane $(10 \mathrm{~mL})$ with stirring at $0^{\circ} \mathrm{C}$. After the reaction was continued for $1 \mathrm{~h}$ at $0^{\circ} \mathrm{C}$, water $(50 \mathrm{~mL})$ was added to the reaction mixture, and the aqueous layer was extracted with dichloromethane. The combined organic extracts were dried over anhydrous $\mathrm{MgSO}_{4}$ and concentrated in vacuo after filtration. The crude product was purified by column chromatography on silica gel (hexane/ethyl acetate $=3 / 1, \mathrm{v} / \mathrm{v})$ to afford pure $2(3.5 \mathrm{~g}$, $67 \%$ yield): ${ }^{1} \mathrm{H}$ NMR $\left(400 \mathrm{MHz}, \mathrm{CDCl}_{3}\right) \delta 1.30(\mathrm{t}, 3 \mathrm{H}$, $\left.J=7.2 \mathrm{~Hz}, \mathrm{CH}_{3}\right), 1.34\left(\mathrm{~d}, 3 \mathrm{H}, J=6.4 \mathrm{~Hz}, \mathrm{CH}_{3}\right), 1.68(\mathrm{br}$, $1 \mathrm{H}, \mathrm{NH}), 3.20-3.40\left(\mathrm{~m}, 2 \mathrm{H}, \mathrm{CH}_{2} \mathrm{~N}\right), 3.78(\mathrm{q}, 1 \mathrm{H}$, $J=6.4 \mathrm{~Hz}, \mathrm{NCH}), 4.20\left(\mathrm{q}, 2 \mathrm{H}, J=7.2 \mathrm{~Hz}, \mathrm{OCH}_{2}\right), 5.65$ (s, 1H, vinyl), 6.23(s, 1H, vinyl), $7.22-7.35(\mathrm{~m}, 5 \mathrm{H}$, aromatic); IR (neat, $\mathrm{cm}^{-1}$ ) 3336, 1713, 1631, 1492, 1450, 1369, 1304, 1264, 1176, 1158, 1116, 1027; Elemental anal. Found: C $72.07 \%, \mathrm{H} 8.34 \%$, N 5.98\%. Calcd for $\mathrm{C}_{14} \mathrm{H}_{19} \mathrm{NO}_{2}$ : C $72.07 \%, \mathrm{H} 8.21 \%$, N 6.00\%.

Resolution of racemic 2 was carried out by high-performance liquid chromatography (HPLC) on CHIRALCEL OD $(25 \times 0.46$ (id) $\mathrm{cm} \times 2)$ using hexane/ ethanol $=100 / 1(\mathrm{v} / \mathrm{v})$ as an eluent.

$(R)-2 \quad(2 \mathrm{R}):[\alpha]_{\mathrm{D}}^{25}=+26^{\circ}, \quad[\alpha]_{365}^{25}=+52^{\circ} \quad(c=1.1$, $\mathrm{CHCl}_{3}$ ); Elemental anal. Found: $\mathrm{C} 72.05 \%, \mathrm{H} 8.36 \%, \mathrm{~N}$ $6.04 \%$. Calcd for $\mathrm{C}_{14} \mathrm{H}_{19} \mathrm{NO}_{2}$ : C $72.07 \%, \mathrm{H} 8.21 \%, \mathrm{~N}$ $6.00 \%$.
$(S)-2 \quad(2 S): \quad[\alpha]_{\mathrm{D}}^{25}=-25^{\circ}, \quad[\alpha]_{365}^{25}=-51^{\circ} \quad(c=2.0$, $\mathrm{CHCl}_{3}$ ); Elemental anal. Found: $\mathrm{C} 72.07 \%, \mathrm{H} 8.08 \%, \mathrm{~N}$ $6.12 \%,$. Calcd for $\mathrm{C}_{14} \mathrm{H}_{19} \mathrm{NO}_{2}: \mathrm{C} 72.07 \%, \mathrm{H} 8.21 \%, \mathrm{~N}$ $6.00 \%$.

Other Acrylates. Monomers $\mathbf{3}-\mathbf{8}$ were synthesized by a similar procedure using the corresponding amines; yields were over $90 \%$.

Ethyl $\alpha-[N-($ Diphenylmethyl)aminomethyl $]$ acrylate (3): ${ }^{1} \mathrm{H}$ NMR $\left(400 \mathrm{MHz}, \mathrm{CDCl}_{3}\right) \delta 1.28(\mathrm{t}, 3 \mathrm{H}, J=7.2 \mathrm{~Hz}$, $\mathrm{CH}_{3}$ ), 1.96 (br, 1H, NH), 3.44 (s, $\left.2 \mathrm{H}, \mathrm{CH}_{2} \mathrm{~N}\right), 4.20$ (q, $\left.2 \mathrm{H}, J=7.2 \mathrm{~Hz}, \mathrm{OCH}_{2}\right), 4.84(\mathrm{~s}, 1 \mathrm{H}, \mathrm{NCH}), 5.68(\mathrm{~s}, 1 \mathrm{H}$, vinyl), 6.27 (s, 1H, vinyl), 7.17-7.41 (m, 10H, aromatic); IR (neat, $\mathrm{cm}^{-1}$ ) 3336, 1712, 1630, 1492, 1452, 1369, 1322, 1301, 1218, 1153, 1107, 1028; Elemental anal. Found: C $77.46 \%, \mathrm{H} 7.17 \%, \mathrm{~N} 4.74 \%$. Calcd for $\mathrm{C}_{19} \mathrm{H}_{21} \mathrm{NO}_{2}$ : C $77.26 \%, \mathrm{H} 7.17 \%, \mathrm{~N} 4.74 \%$.

Ethyl $\alpha-[N-($ Triphenylmethyl)aminomethyl $]$ acrylate (4): mp 67.5-68.1 ${ }^{\circ} \mathrm{C} ;{ }^{1} \mathrm{H}$ NMR $\left(400 \mathrm{MHz}, \mathrm{CDCl}_{3}\right) \delta 1.26$ (t, 3H, J=7.2 Hz, $\mathrm{CH}_{3}$ ), 1.95 (br, 1H, NH), 2.96 (s, 2H, $\left.\mathrm{CH}_{2} \mathrm{~N}\right), 4.17\left(\mathrm{q}, 2 \mathrm{H}, J=7.2 \mathrm{~Hz}, \mathrm{OCH}_{2}\right), 5.95(\mathrm{~s}, 1 \mathrm{H}$, vinyl), 6.27 (s, 1H, vinyl), 7.16-7.51 (m, 15H, aromatic); IR (neat, $\mathrm{cm}^{-1}$ ) 3398, 1714, 1631, 1490, 1476, 1447, 1401, 1377, 1295, 1207, 1153, 1111, 1088, 1024; Elemental anal. Found: C $80.76 \%, \mathrm{H} 6.87 \%, \mathrm{~N} 3.64 \%$. Calcd for $\mathrm{C}_{25} \mathrm{H}_{25} \mathrm{NO}_{2}$ : C $80.83 \%$, H 6.78\%, N 3.77\%.

Ethyl $\alpha$-(Anilinomethyl)acrylate (5): bp $144-146^{\circ} \mathrm{C} /$ $3 \mathrm{mmHg} ;{ }^{1} \mathrm{H}$ NMR $\left(400 \mathrm{MHz}, \mathrm{CDCl}_{3}\right) \delta 1.31(\mathrm{~s}, 3 \mathrm{H}$, $\left.J=7.2 \mathrm{~Hz}, \mathrm{CH}_{3}\right), 4.03\left(\mathrm{~m}, 2 \mathrm{H}, \mathrm{CH}_{2} \mathrm{~N}\right), 4.07$ (br, $1 \mathrm{H}$, $\mathrm{NH}), 4.24$ (q, 2H, $\left.J=7.2 \mathrm{~Hz}, \mathrm{OCH}_{2}\right), 5.78$ (s, $1 \mathrm{H}$, vinyl), 6.27 ( $\mathrm{s}, 1 \mathrm{H}$, vinyl), $6.60(\mathrm{~d}, 2 \mathrm{H}, J=7.2 \mathrm{Mz}$, aromatic), $6.61(\mathrm{t}, 1 \mathrm{H}, J=7.2 \mathrm{~Hz}$, aromatic). $7.17(\mathrm{t}, 2 \mathrm{H}, J=7.2 \mathrm{~Hz}$, aromatic); IR (neat, $\mathrm{cm}^{-1}$ ) 3416, 1710, 1598, 1579, 1509, 1371, 1296, 1267, 1152, 1099, 1072, 1026, 949; Elemental anal. Found: C $70.12 \%, \mathrm{H} 7.57 \%, \mathrm{~N} 6.58 \%$. Calcd for $\mathrm{C}_{12} \mathrm{H}_{15} \mathrm{NO}_{2}$ : C $70.22 \%, \mathrm{H} 7.37 \%$, N 6.82\%.

Ethyl $\alpha-[(3,5-D i m e t h y l a n i l i n o)$ methyl $]$ acrylate $(6):{ }^{1} \mathrm{H}$ NMR (400 MHz, $\left.\mathrm{CDCl}_{3}\right) \delta 1.32\left(\mathrm{~s}, 3 \mathrm{H}, J=7.2 \mathrm{~Hz}, \mathrm{CH}_{3}\right)$, $2.22\left(\mathrm{~s}, 6 \mathrm{H}, \mathrm{CH}_{3}\right), 3.96(\mathrm{br}, 1 \mathrm{H}, \mathrm{NH}), 4.00(\mathrm{~m}, 2 \mathrm{H}$, $\left.\mathrm{CH}_{2} \mathrm{~N}\right), 4.24\left(\mathrm{q}, 2 \mathrm{H}, J=7.2 \mathrm{~Hz}, \mathrm{OCH}_{2}\right), 5.77(\mathrm{~s}, 1 \mathrm{H}$, vinyl), $6.25(\mathrm{~s}, 2 \mathrm{H}$, aromtic), $6.26(\mathrm{~s}, 1 \mathrm{H}$, vinyl), $6.37(\mathrm{~s}$, $1 \mathrm{H}$, aromatic); IR (neat, $\mathrm{cm}^{-1}$ ) 3410, 1713, 1602, 1516, 1476, 1370, 1337, 1295, 1231, 1149, 1105, 1026; Elemental anal. Found: C $71.92 \%, \mathrm{H} 8.58 \%, \mathrm{~N} 6.02 \%$. Calcd for $\mathrm{C}_{14} \mathrm{H}_{19} \mathrm{NO}_{2}$ : C $72.07 \%, \mathrm{H} 8.21 \%$, N 6.00\%,

Ethyl $\alpha-[(3,5-$ Dimethoxyanilino $)$ methyl $]$ acrylate (7): ${ }^{1} \mathrm{H}$ NMR $\left(400 \mathrm{MHz}, \mathrm{CDCl}_{3}\right) \delta 1.31(\mathrm{t}, 3 \mathrm{H}, J=7.2 \mathrm{~Hz}$, $\left.\mathrm{CH}_{3}\right), 3.74\left(\mathrm{~s}, 6 \mathrm{H}, \mathrm{CH}_{3}\right), 4.00\left(\mathrm{~m}, 2 \mathrm{H}, \mathrm{CH}_{2} \mathrm{~N}\right), 4.09(\mathrm{br}$, $1 \mathrm{H}, \mathrm{NH}), 4.23\left(\mathrm{q}, 2 \mathrm{H}, J=7.2 \mathrm{~Hz}, \mathrm{OCH}_{2}\right), 5.77(\mathrm{~s}, 1 \mathrm{H}$, vinyl), 5.77 (s, 1H, aromatic), $5.78(\mathrm{~s}, 1 \mathrm{H}$, aromatic), 5.88 (s, 1H, aromatic), $6.26\left(\mathrm{~s}, 1 \mathrm{H}\right.$, vinyl); IR (neat, $\mathrm{cm}^{-1}$ ) $3410,1716,1615,1520,1456,1372,1296,1264,1145$, 1101, 1070, 1026; Elemental anal. Found: C 63.23\%, H $7.58 \%$, N 5.31\%. Calcd for $\mathrm{C}_{14} \mathrm{H}_{19} \mathrm{NO}_{4}$ : C $63.38 \%, \mathrm{H}$ $7.22 \%, \mathrm{~N} 5.28 \%$.

Ethyl $\alpha-[(3,5$-Dichloroanilino $)$ methyl $]$ acrylate $(\mathbf{8}): \mathrm{mp}$ $39.0-40.0^{\circ} \mathrm{C} ;{ }^{1} \mathrm{H}$ NMR $\left(400 \mathrm{MHz}, \mathrm{CDCl}_{3}\right) \delta 1.32(\mathrm{t}$, $\left.3 \mathrm{H}, J=7.2 \mathrm{~Hz}, \mathrm{CH}_{3}\right), 3.99\left(\mathrm{~m}, 2 \mathrm{H}, \mathrm{CH}_{2} \mathrm{~N}\right), 4.25(\mathrm{br}, 1 \mathrm{H}$, $\mathrm{NH}), 4.25$ (q, 2H, $\left.J=7.2 \mathrm{~Hz}, \mathrm{OCH}_{2}\right), 5.74$ (s, 1H, vinyl), $6.29(\mathrm{~s}, 1 \mathrm{H}$, vinyl), $6.44(\mathrm{~s}, 2 \mathrm{H}$, aromatic), $6.75(\mathrm{~s}, 1 \mathrm{H}$, aromatic); IR (neat, $\mathrm{cm}^{-1}$ ) 3402, 1709, 1592, 1505, 1457, 1405, 1371, 1322, 1302, 1264, 1175, 1113, 1088; Elemental anal. Found: C 52.53\%, H 4.99\%, N 5.17\%. Calcd for $\mathrm{C}_{12} \mathrm{H}_{13} \mathrm{NO}_{2} \mathrm{Cl}_{2}$ : C $52.57 \%$, H $4.78 \%$, N $5.11 \%$. 
H. Baraki, S. Habaue, and Y. OKamoto

Table I. Anionic polymerization of $\alpha$-(N-alkylaminomethyl)acrylates at $-78^{\circ} \mathrm{C}^{\mathrm{a}}$

\begin{tabular}{|c|c|c|c|c|c|c|}
\hline Entry & Monomer & Initiator & Conditions & Yield $/ \%^{b}$ & $M_{n} \times 10^{-4}(\mathrm{DP})^{\mathrm{c}}$ & $f^{\mathrm{d}}$ \\
\hline 1 & 2 & $n$-BuLi & Toluene, $24 \mathrm{~h}$ & 2 & & \\
\hline 2 & 2 & $\mathrm{Ph}_{2} \mathrm{NLi}^{-T M E D A}{ }^{\mathrm{e}}$ & Toluene, $24 \mathrm{~h}$ & 90 & $0.9(36)$ & 0.47 \\
\hline 3 & 2 & DPEDALi ${ }^{\mathrm{f}}-(-) \mathrm{Sp}^{\mathrm{g}}$ & Toluene, $4 \mathrm{~h}$ & $87^{\mathrm{h}}$ & & \\
\hline 4 & 2 & DPEDALi- $(+)$ PMP $^{\mathrm{i}}$ & Toluene, $4 \mathrm{~h}$ & $93^{j}$ & & \\
\hline 5 & 2 & DPEDALi- $\left.^{-}+\right)$DDB $^{k}$ & Toluene, $4 \mathrm{~h}$ & $24^{1}$ & & \\
\hline 6 & 2 & $\mathrm{Ph}_{2} \mathrm{NLi}$ & THF, $24 \mathrm{~h}$ & 89 & $1.2(51)$ & 0.35 \\
\hline $8^{\mathrm{m}}$ & 3 & $\mathrm{Ph}_{2}$ NLi-TMEDA & Toluene, $30 \mathrm{~h}$ & 96 & $1.2(41)$ & 0.47 \\
\hline $9^{m}$ & 3 & $\mathrm{Ph}_{2} \mathrm{NLi}$ & THF, $30 \mathrm{~h}$ & 94 & $1.2(41)$ & 0.46 \\
\hline $10^{\mathrm{n}}$ & 4 & $n$-BuLi & Toluene, $24 \mathrm{~h}$ & 0 & & \\
\hline $11^{\mathrm{n}}$ & 4 & $\mathrm{Ph}_{2} \mathrm{NLi}-\mathrm{TMEDA}$ & Toluene, $24 \mathrm{~h}$ & 0 & & \\
\hline
\end{tabular}

${ }^{\mathrm{a}}[$ Monomer $]=1.0 \mathrm{M},[$ Monomer $] /[$ Initiator $]=20 .{ }^{\mathrm{b}} \mathrm{MeOH}$ insoluble part. ${ }^{\mathrm{c}}$ Determined by $\mathrm{VPO}$ (solvent $\mathrm{CHCl} 3{ }_{3}$ benzil standard). ${ }^{\mathrm{d}}$ Efficiency of initiator. ${ }^{\mathrm{e}} N, N, N^{\prime}, N^{\prime}$-Tetramethylethylenediamine. ${ }^{\mathrm{f}} N, N^{\prime}$-Diphenylethylenediamine monolithium amide. ${ }^{\mathrm{g}}(-)$-Sparteine. ${ }^{\mathrm{h}}[\alpha]_{365}-4^{\circ}\left(c\right.$ 1.0, in $\left.\mathrm{CHCl}_{3}, 25^{\circ} \mathrm{C}\right) . \quad{ }^{\mathrm{i}}(S)-(+)-1-(2-\mathrm{Pyrrolidinylmethyl})$ pyrrolidine. ${ }^{\mathrm{j}}[\alpha]_{365}-6^{\circ}\left(c 1.0\right.$, in $\left.\mathrm{CHCl}_{3}, 25^{\circ} \mathrm{C}\right) .{ }^{\mathrm{k}}(S, S)-(+)-2,3-$ Dimethoxy-1,4-bis(dimethylamino)butane. ${ }^{1}[\alpha]_{365}-6^{\circ}\left(c 1.0\right.$, in $\left.\mathrm{CHCl}_{3}, 25^{\circ} \mathrm{C}\right)$. ${ }^{\mathrm{m}}[\mathrm{Monomer}]=0.2 \mathrm{M}$. ${ }^{\mathrm{n}}[\mathrm{Monomer}]=0.1 \mathrm{M}$.

\section{Polymerization Procedure}

Polymerization was carried out in a glass ampule equipped with a three-way stopcock. Purified reagents were transferred to the ampule by syringe under dry nitrogen. The polymerization was initiated by adding an initiator solution to a monomer solution, typically using $2.0 \mathrm{~mL}$ of a monomer solution $([\mathrm{M}]=1.0,2.0 \mathrm{mmol})$ and initiator $(0.1 \mathrm{mmol})$. Termination of the polymerization was done by adding a small amount of methanol and polymers were precipitated in excess methanol. The polymers were separated by centrifugation and dried in vacuo.

\section{RESULTS AND DISCUSSION}

\section{Polymerization of $\alpha-(N$-Alkylaminomethyl $)$ acrylates}

The results of the anionic polymerization of ethyl $\alpha-(N$-alkylaminomethyl)acrylates $(2-4)$ in toluene or THF are summarized in Table I. The polymerization of 2 with $n$-BuLi at $-78^{\circ} \mathrm{C}$ (Table I, entry 1 ) as well as that of 1 reported previously, ${ }^{4}$ proceeded in poor yields $(<$ $3 \%$ ). Abstraction of an $\mathrm{NH}$ proton by a strong base $n$-BuLi may occur and the resulting lithium amide may not initiate the polymerization. In contrast, the polymerization of 3 with $n$ - BuLi at $-78^{\circ} \mathrm{C}$ provided a polymer in a moderate yield (63\%) (Table I, entry 7$)$, probably because the side reaction of unprotected amino proton with $n$-BuLi was prevented to a certain extent by the steric hindrance of bulky diphenylmethyl group. Polymerization of 2 and 3 using $\mathrm{Ph}_{2} \mathrm{NLi}$ and its complex with diamine (TMEDA) at $-78^{\circ} \mathrm{C}$ in toluene and THF resulted in good yields (Table I, entries 2, 6, 8, and 9). The lower basisity of $\mathrm{Ph}_{2} \mathrm{NLi}$ appears to efficiently initiate the polymerization without abstraction of an NH proton.

The obtained polymers are soluble in $\mathrm{CHCl}_{3}$ and THF. The ${ }^{1} \mathrm{H}$ NMR spectrum of the polymer obtained from 3 with the $\mathrm{Ph}_{2}$ NLi-TMEDA complex in toluene (Table I, entry 8) is demonstrated in Figure 1. Although the peak of the main chain methylene protons overlaps with that of the amino proton around $2.2 \mathrm{ppm}$, the spectral pattern is simple. Figure 2 shows the ${ }^{13} \mathrm{C}$ NMR spectrum of the same polymer. All peaks are sharp and assigned to a vinyl polymer corresponding to poly(3) as shown in the figures. Chain-transfer reaction (hydrogen-transfer

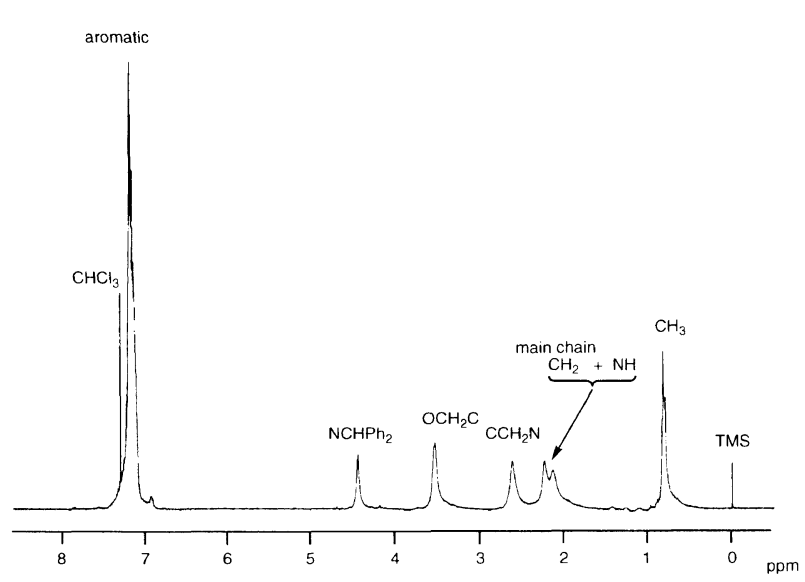

Figure 1. $400 \mathrm{MHz}{ }^{1} \mathrm{H}$ NMR spectrum of poly(3) obtained with $\mathrm{Ph}_{2} \mathrm{NLi}-\mathrm{TMEDA}$ in toluene at $-78^{\circ} \mathrm{C}$ (Table I, Entry 8) (measured in $\mathrm{CDCl}_{3}$ at $60^{\circ} \mathrm{C}$ ).

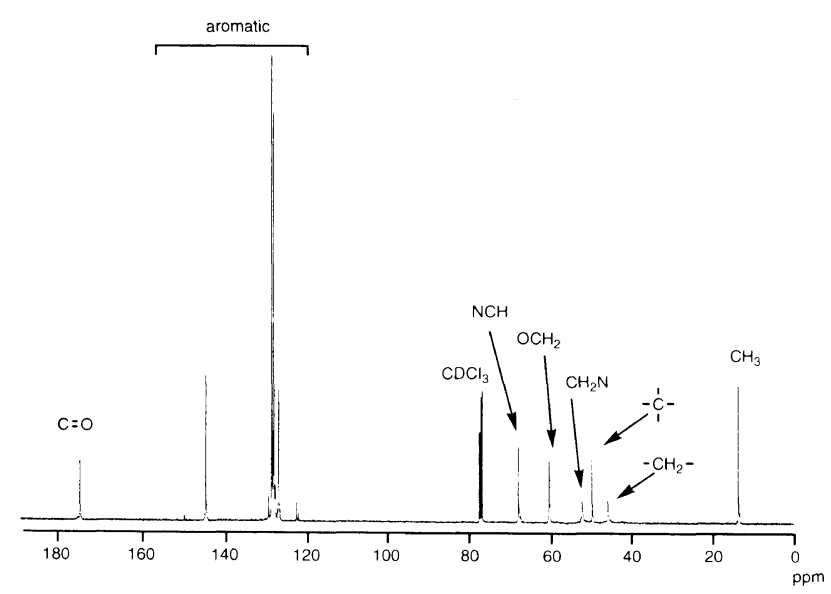

Figure 2. $100 \mathrm{MHz}{ }^{13} \mathrm{C}$ NMR spectrum of poly(3) obtained with $\mathrm{Ph}_{2} \mathrm{NLi}-\mathrm{TMEDA}$ in toluene at $-78^{\circ} \mathrm{C}$ (Table I, Entry 8) (measured in $\mathrm{CDCl}_{3}$ at $60^{\circ} \mathrm{C}$ ).

reaction) from the growing polymer chain end to the reactive unprotected amino group thus hardly occurs. The ${ }^{13} \mathrm{C}$ NMR spectra of the carbonyl carbon in the poly(3) obtained with $n$-BuLi (Table I, entry 7) and the $\mathrm{Ph}_{2}$ NLi-TMEDA complex in toluene (Table I, entry 8) are demonstrated in Figures 3(a) and 3(b), respectively. A sharp singlet at the same chemical shift is observed in Figure 3(a) and 3(b), indicating that the polymers 
obtained from $\mathbf{3}$ in toluene are highly stereoregular vinyl polymers. The polymer obtained from 1 with the $\mathrm{Ph}_{2} \mathrm{NLi}$-TMEDA complex in toluene was isotactic $(m m=83 \%)$, while that in THF, rich in syndiotacticity. ${ }^{4}$ Therefore, the poly(3)s obtained in toluene must be highly isotactic. Although the ${ }^{13} \mathrm{C}$ NMR spectrum of carbonyl carbon in the polymer obtained with $\mathrm{Ph}_{2} \mathrm{NLi}$ in THF showed multi peaks with mostly different chemical shifts from that for highly isotactic poly(3) (Figure 3(c)), the ${ }^{1} \mathrm{H}$ NMR spectrum of the same polymer was assigned to a normal vinyl polymer structure corresponding to poly(3). Therefore, the polymer generated in THF must have a quite different tacticity from those prepared in toluene, probably high syndiotacticity judging from the results of the polymerization of $1 .{ }^{4}$

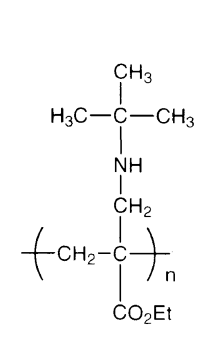

poly (1)

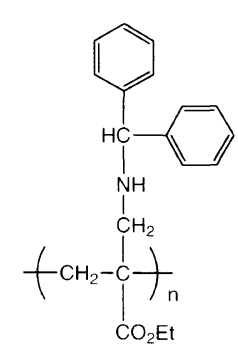

poly (3)
The polymerization of racemic 2 using various chiral initiators with optically active ligands afforded the polymers possessing a small optical rotation (Table I, entries 3-5). HPLC analysis of unreacted monomer indicated that enantiomer-selective polymerization ${ }^{12-14}$ hardly took place under these conditions. ${ }^{1} \mathrm{H}$ and ${ }^{13} \mathrm{C}$

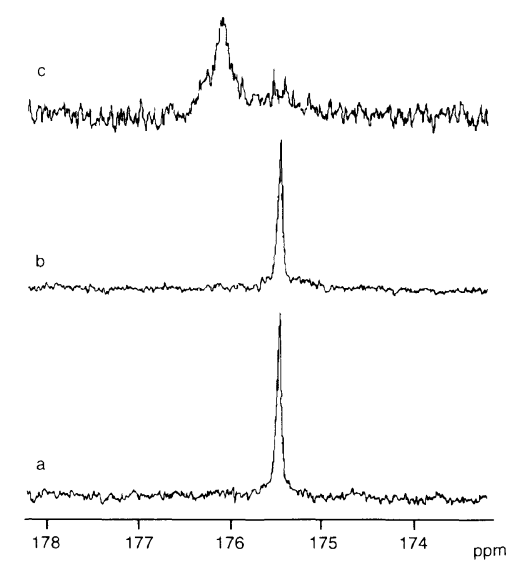

Figure 3. $100 \mathrm{MHz}{ }^{13} \mathrm{C}$ NMR spectra of the carbonyl carbon in poly(3) obtained with (a) $n$-BuLi in toluene (Table I, Entry 7), (b) $\mathrm{Ph}_{2}$ NLi-TMEDA in toluene (Table I, Entry 8), and (c) $\mathrm{Ph}_{2} \mathrm{NLi}$ in THF (Table I, Entry 9) (measured in $\mathrm{CDCl}_{3}$ at $60^{\circ} \mathrm{C}$ ).
NMR spectra of the obtained polymers were very broad (Figure 4), because $\mathbf{2}$ is a mixture of enantiomeric monomers with a chiral center on the amino group ${ }^{15}$ in addition to the $\mathrm{H}$-transfer from the amino proton occurred in polymerization process.

The anionic polymerization of $\mathbf{4}$ bearing the most bulky amino group in toluene at $-78^{\circ} \mathrm{C}$ did not proceed (Table I, entries 10 and 11), probably due to the bulkiness of $\alpha$-substituent which may prevent polymerization as reported previously for the anionic polymerization of $\alpha$-(trityloxymethyl)acrylate having a bulky alkoxy group. ${ }^{16}$

\section{Polymerization of Optically Active $\mathbf{2} \boldsymbol{R}$ and $\mathbf{2 S}$}

The results of the anionic polymerization of optically active $\mathbf{2 R}$ and $2 \mathbf{S}$ are listed in Table II. Polymerizations in toluene and THF resulted in good yields. The obtained polymers are soluble in $\mathrm{CHCl}_{3}$ and THF. The ${ }^{13} \mathrm{C} \mathrm{NMR}$ spectrum of the carbonyl carbon in the polymer obtained from 2R with $\mathrm{Ph}_{2} \mathrm{NLi}$-TMEDA in toluene (Table II, entry 1) is shown in Figure 5(a). A sharp singlet with a small shoulder suggests a stereoregular polymer. Figures 5(b) and 5(c) show the spectra of the polymers obtained from $\mathbf{2 R}$ with DPEDALi-(-)Sp (Table II, entry 3 ) in toluene and $\mathrm{Ph}_{2} \mathrm{NLi}$ in THF (Table II, entry 4), respectively. A broad peak appeared at lower-magnetic field around $176 \mathrm{ppm}$ in both Figures 5(b) and 5(c). The peak at $175.3 \mathrm{ppm}$ in Figure 5(c) is much broader than those in Figures 5(a) and 5(b).

${ }^{1} \mathrm{H}$ and ${ }^{13} \mathrm{C}$ NMR spectra of the polymers obtained from $2 \mathbf{R}$ with $\mathrm{Ph}_{2} \mathrm{NLi}$-TMEDA in toluene (a) and $\mathrm{Ph}_{2} \mathrm{NLi}$ in THF (b) are shown in Figures 6 and 7 , respectively. In Figure 7 , spectral patterns of the main

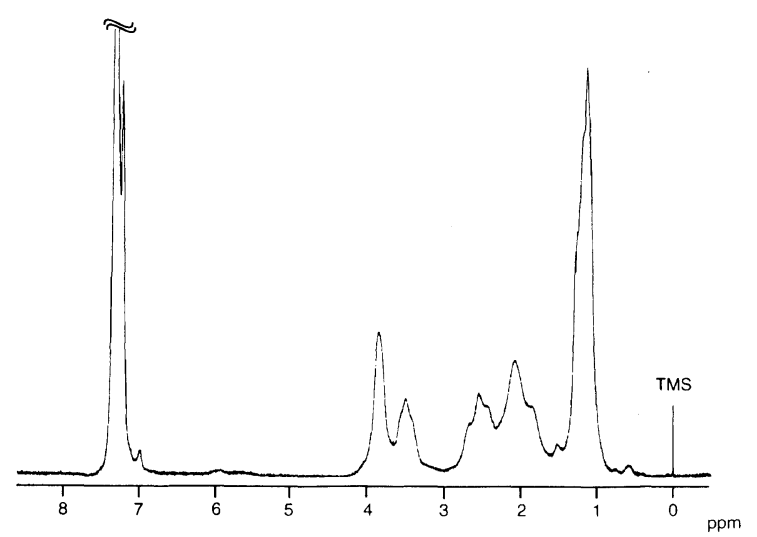

Figure 4. $400 \mathrm{MHz}{ }^{1} \mathrm{H}$ NMR spectrum of the polymer obtained from 2 with $\mathrm{Ph}_{2} \mathrm{NLi}$-TMEDA in toluene at $-78^{\circ} \mathrm{C}$ (Table I, Entry 2) (measured in $\mathrm{CDCl}_{3}$ at $60^{\circ} \mathrm{C}$ ).

Table II. Anionic polymerization of optically active $2 \mathrm{R}$ and $2 \mathrm{~S}$ at $-78^{\circ} \mathrm{C}^{\mathrm{a}}$

\begin{tabular}{cclccccc}
\hline Enty & Monomer & \multicolumn{1}{c}{ Initiator } & Conditions & Yield $/ \%^{\mathbf{b}}$ & $M_{n} \times 10^{-4}(\mathrm{DP})^{\mathbf{c}}$ & $f^{\mathbf{d}}$ & {$[\alpha]_{365^{\mathrm{e}}}$} \\
\hline 1 & $\mathbf{2 R}$ & $\mathrm{Ph}_{2}$ NLi-TMEDA & Toluene, 5h & 80 & $0.8(34)$ & 0.47 & $+238^{\circ}$ \\
2 & $\mathbf{2 R}$ & $\mathrm{Ph}_{2}$ NLi-(-)Sp & Toluene, 24h & 73 & $0.6(26)$ & 0.57 & $+219^{\circ}$ \\
3 & $\mathbf{2 R}$ & DPEDALi-(-)Sp & Toluene, 5h & 79 & $0.8(34)$ & 0.46 & $+263^{\circ}$ \\
4 & $\mathbf{2 R}$ & $\mathrm{Ph}_{2}$ NLi & THF, 24h & 74 & $0.6(26)$ & 0.58 & $+274^{\circ}$ \\
5 & $\mathbf{2 S}$ & $\mathrm{Ph}_{2}$ NLi-TMEDA & Toluene, 5h & 83 & $0.8(34)$ & 0.48 & $-227^{\circ}$ \\
6 & $\mathbf{2 S}$ & $\mathrm{Ph}_{2} \mathrm{NLi}$ & THF, 24h & 74 & $0.6(26)$ & 0.58 & $-238^{\circ}$ \\
\hline
\end{tabular}

${ }^{\mathrm{a}}[$ Monomer $]=1.0 \mathrm{M},[$ Monomer $] /[$ Initiator $]=20 . \quad{ }^{\mathrm{b}} \mathrm{MeOH}$ insoluble part. $\quad{ }^{\mathrm{c}}$ Determined by VPO (solvent $\mathrm{CHCl}_{3}$, benzil standard). ${ }^{\mathrm{d}}$ Efficiency of initiator. ${ }^{\mathrm{e}}$ Measured in $\mathrm{CHCl}_{3}, c 1.0$, temp $25^{\circ} \mathrm{C}$. 

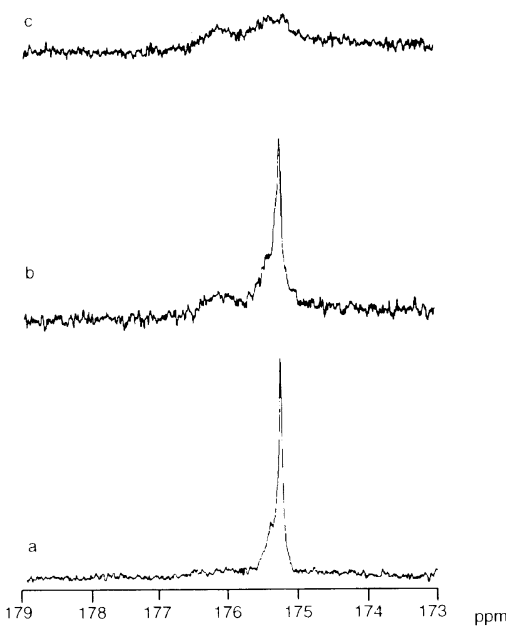

Figure 5. $100 \mathrm{MHz}{ }^{13} \mathrm{C}$ NMR spectra of the carbonyl carbon of polymers obtained from $2 \mathrm{R}$ with (a) $\mathrm{Ph}_{2} \mathrm{NLi}$-TMEDA in toluene (Table II, Entry 1), (b) DPEDALi-(-)Sp in toluene (Table II, Entry 3), and (c) $\mathrm{Ph}_{2} \mathrm{NLi}$ in THF (Table II, Entry 4) (measured in $\mathrm{CDCl}_{3}$ at $60^{\circ} \mathrm{C}$ ).

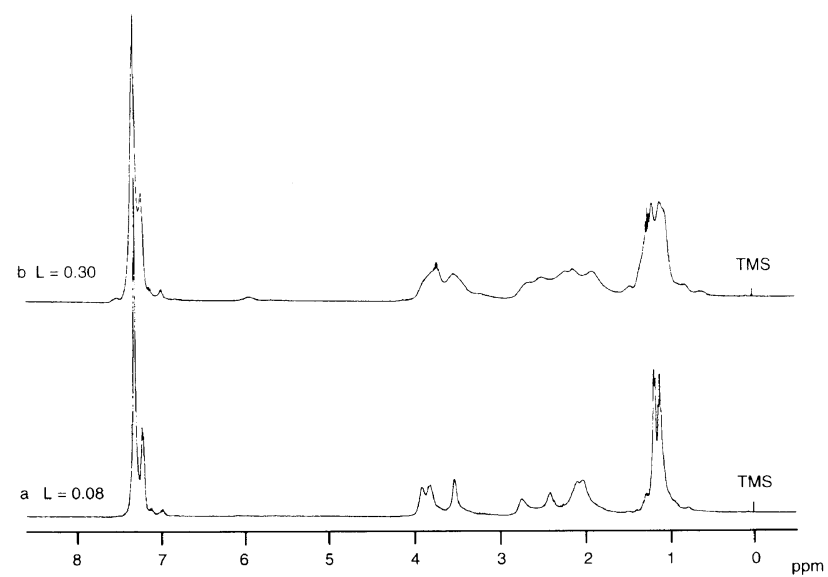

Figure 6. $400 \mathrm{MHz}{ }^{1} \mathrm{H}$ NMR spectra of polymers obtained from $\mathbf{2 R}$ with (a) $\mathrm{Ph}_{2} \mathrm{NLi}$-TMEDA in toluene (Table II, Entry $1, \mathrm{~L}=0.08$ ) and (b) $\mathrm{Ph}_{2} \mathrm{NLi}$ in THF (Table II, Entry $4, \mathrm{~L}=0.30$ ) (measured in $\mathrm{CDCl}_{3}$ at $60^{\circ} \mathrm{C}$ ).

chain carbons around 40-50 ppm and carbonyl carbon at $175 \mathrm{ppm}$ in the polymers are quite different. The methyl carbon of the ester group (marked with an arrow in Figure 7) showed two peaks at $13.8 \mathrm{ppm}$ and $15.4 \mathrm{ppm}$, although the tacticity hardly affects the spectral pattern in ${ }^{13} \mathrm{C}$ NMR measurement of poly(1) and poly(3), which show a single peak regardless of the tacticity. To obtain further information on the structure, distortionless enhancement by polarization transfer (DEPT) NMR measurement was performed for the polymer obtained from $\mathbf{2 R}$ with $\mathrm{Ph}_{2} \mathrm{NLi}-(-) \mathrm{Sp}$ in toluene (Table II, entry 2). A broad peak around $52 \mathrm{ppm}$ in Figure 8(b) can be assigned to the main chain $\mathrm{CH}$ that would be generated by transfer of the amino proton to the propagation chain end during polymerization. The poly(2)s thus likely contain the $\mathrm{H}$-transfer unit in addition to the vinyl polymerization unit. The $\mathrm{H}$-transfer polymerization was reported previously for the anionic polymerization of $\alpha$ - and $\beta$-substituted acrylamide, $N$-substituted acrylamide, and $p$-vinylbenzamide, ${ }^{5-10}$ which gave polyamides through the $\mathrm{H}$-transfer of the amide proton. The two peaks due to methyl carbons of the ester group in

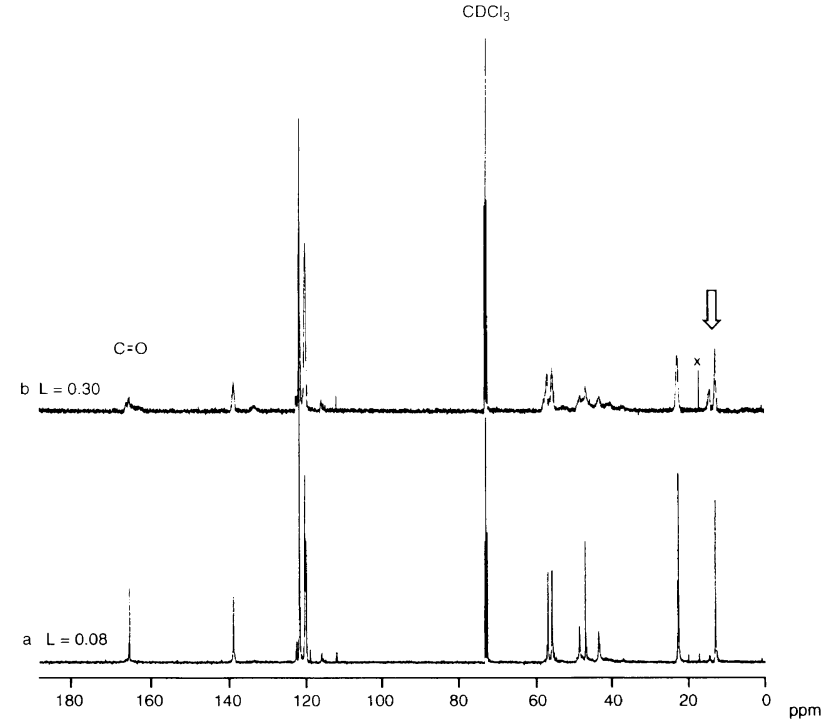

Figure 7. $100 \mathrm{MHz}{ }^{13} \mathrm{C} \mathrm{NMR}$ spectra of polymers obtained from $\mathbf{2 R}$ with (a) $\mathrm{Ph}_{2}$ NLi-TMEDA in toluene (Table II, Entry $1, \mathrm{~L}=0.08$ ) and (b) $\mathrm{Ph}_{2} \mathrm{NLi}$ in THF (Table II, Entry $4, \mathrm{~L}=0.30$ ) (measured in $\mathrm{CDCl}_{3}$ at $60^{\circ} \mathrm{C}$ ).

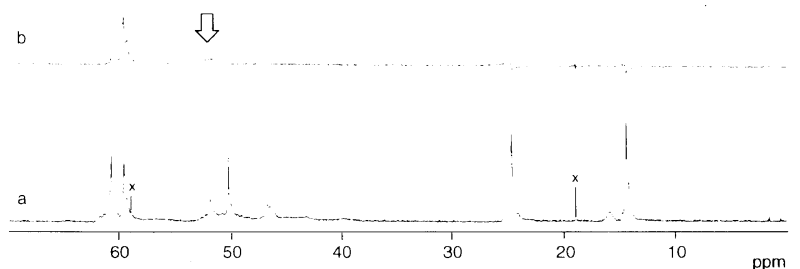

Figure 8. (a) $125 \mathrm{MHz}^{13} \mathrm{C}$ NMR and (b) distortionless enhancement by polarization transfer (DEPT) NMR, where carbons with only one proton yield active signals; spectra of the polymer obtained from $\mathbf{2 R}$ with $\mathrm{Ph}_{2} \mathrm{NLi}-(-) \mathrm{Sp}$ in toluene at $-78^{\circ} \mathrm{C}$ (Table II, Entry $2, \mathrm{~L}=0.19$ ) (measured in $\mathrm{CDCl}_{3}$ at $55^{\circ} \mathrm{C}$ ).

Table III. Relative intensity ratio in ${ }^{13} \mathrm{C}$ NMR spectra of methyl carbon of ester group in poly $(\mathbf{2 R})$ and $\operatorname{poly}(\mathbf{2})$

\begin{tabular}{|c|c|c|c|c|}
\hline Entry & Monomer & Initiator & Solvent & $\begin{array}{l}\text { Lower-magnetic field } \\
(\mathrm{L}) \text { : Higher- } \\
\text { magnetic field }(\mathrm{H})^{\mathrm{a}} \\
(\mathrm{L}+\mathrm{H}=1)\end{array}$ \\
\hline 1 & 2R & $\mathrm{Ph}_{2} \mathrm{NLi}^{\mathrm{N}} \mathrm{TMEDA}$ & Toluene & $0.08: 0.92$ \\
\hline 2 & 2R & $\mathrm{Ph}_{2} \mathrm{NLi}-(-) \mathrm{Sp}$ & Toluene & $0.19: 0.81$ \\
\hline 3 & 2R & DPEDALi- $(-)$ Sp & Toluene & $0.20: 0.80$ \\
\hline 4 & 2R & $\mathrm{Ph}_{2} \mathrm{NLi}$ & THF & $0.30: 0.70$ \\
\hline 5 & 2 & $\mathrm{Ph}_{2} \mathrm{NLi}-\mathrm{TMEDA}$ & Toluene & $0.17: 0.83$ \\
\hline 6 & 2 & DPEDALi- $(+)$ PMP & Toluene & $0.18: 0.82$ \\
\hline 7 & 2 & DPEDALi-(-)Sp & Toluene & $0.29: 0.71$ \\
\hline 8 & 2 & DPEDALi- $(+)$ DDB & Toluene & $0.30: 0.70$ \\
\hline 9 & 2 & $\mathrm{Ph}_{2} \mathrm{NLi}$ & THF & $0.43: 0.57$ \\
\hline
\end{tabular}

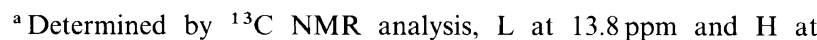
$15.4 \mathrm{ppm}$.

poly(2) may be assigned to those for the $\mathrm{H}$-transfer unit at the lower-magnetic field and vinyl unit at the highermagnetic field, respectively. This assignment is reasonably supported by the ${ }^{1} \mathrm{H}$ and ${ }^{13} \mathrm{C}$ NMR analyses of poly(2)s. On comparing Figure 6(b) with 6(a), the spectral patterns were complicated owing to the $\mathrm{H}$-transfer unit and tacticity. The absorption of methylene protons of main chain in vinyl polymerization unit around $2 \mathrm{ppm}$ 
may decrease and those in the $\mathrm{H}$-transfer unit neighboring nitrogen atom increase. The relative intensity of the two methyl peaks in ${ }^{13} \mathrm{C}$ NMR spectra is summarized in Table III. The relative intensity of the peak at the lower-magnetic field appears to increase under polar polymerization conditions. The polymer having $43 \%$ $\mathrm{H}$-transfer unit was obtained using $\mathrm{Ph}_{2} \mathrm{NLi}$ in THF. The generation of a $\mathrm{H}$-transfer unit was observed only in the anionic polymerizations of $2 \mathrm{~s}$. The sterically less hindered, (1-phenylethyl)aminomethyl group may allow $\mathrm{H}$-transfer. The $\mathrm{H}$-transfer took place more often in the polymerization of racemic 2 than optically pure $\mathbf{2}$ (Table III, entries 1 and 5, 3 and 7, and 4 and 9). This difference may be ascribed to the different arrangements of chiral amino groups around the propagating chain end. The arrangement of heterochiral groups may facilitate the H-transfer.

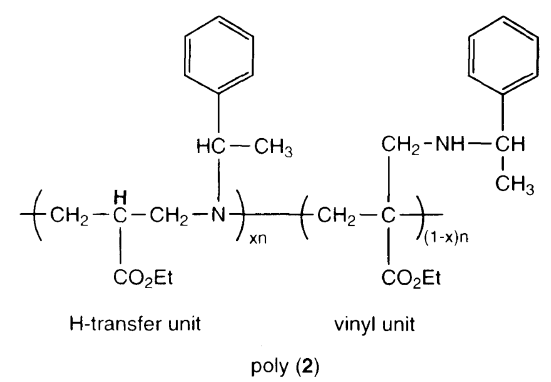

The obtained optically active polymers showed much higher optical rotations than those of the monomers (2R: $[\alpha]_{365}=+52^{\circ} ; 2 \mathrm{~S}:[\alpha]_{365}=-51^{\circ}$ in $\mathrm{CHCl}_{3}$ at $\left.25^{\circ} \mathrm{C}\right)$ (Table II). The CD spectra of $\mathbf{2 R}$ and its polymers (Table II, entries 1, 3, and 4) in $\mathrm{CHCl}_{3}$ are shown in Figure 9. The polymer (Table II, entry 4 ) with a $30 \% \mathrm{H}$-transfer shows slightly larger specific rotation and CD absorption. The spectral patterns of the polymers around $220 \mathrm{~nm}$, which may be due to the ester groups, are quite different from that of the monomer, indicating that the neighboring chiral amino groups in a polymer chain influence the $\mathrm{CD}$ pattern.

\section{Polymerization of $\alpha-($ Anilinomethyl $)$ acrylates}

Table IV shows the results of the anionic polymerization of $\alpha$-(anilinomethyl)acrylates $5-8$ The polymerization of 5,6 , and 7 with $n-\mathrm{BuLi}$ at $-78^{\circ} \mathrm{C}$ in toluene resulted in low yields (Table IV, entries 1, 4, and 7), while the polymerization with the $\mathrm{Ph}_{2} \mathrm{NLi}$-TMEDA complex in toluene provided polymers in good yields (Table IV, entries 2, 5, and 8). The polymerization with $\mathrm{Ph}_{2} \mathrm{NLi}$ in THF afforded polymers in low to poor yields (Table IV, entries 3,6, and 9). The initiator and polarity of solvents greatly affected the polymerizability of these monomers. The polymerization of $\mathbf{8}$ possessing electron withdrawing groups on the phenyl group resulted in poor or no yield (Table IV, entries 10-12). The increase of acidity of the NH proton in the monomer must prevent the anionic polymerization with $n$-BuLi or lithium amide. The obtained polymers are soluble in $\mathrm{CHCl}_{3}$ and THF. The ${ }^{1} \mathrm{H}$ and ${ }^{13} \mathrm{C}$ NMR spectra of the obtained polymers were broad and split in intricate. Meaningful assignment of

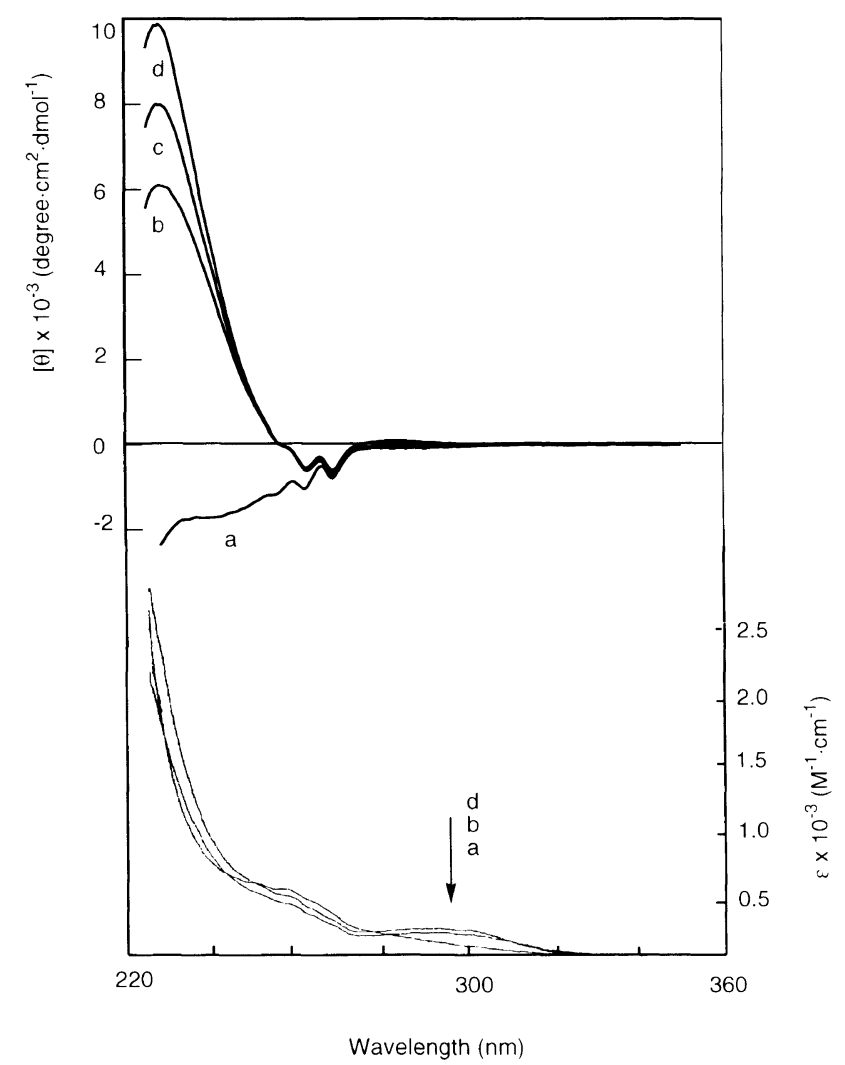

Figure 9. CD (top) and UV (bottom) spectra of (a) the monomer $\mathbf{2 R}$, and polymer obtained from $\mathbf{2 R}$ with (b) $\mathrm{Ph}_{2}$ NLi-TMEDA complex in toluene (Table II, Entry 1), (c) DPEDALi- $(-)$ Sp in toluene (Table II, Entry 3), and (d) $\mathrm{Ph}_{2} \mathrm{NLi}$ in THF (Table II, Entry 4) (measured in $\mathrm{CHCl}_{3}$ at room temperature).

Table IV. Anonic polymerization of $\alpha$-(anilinomethyl)acrylates at $-78^{\circ} \mathrm{C}^{\mathrm{a}}$

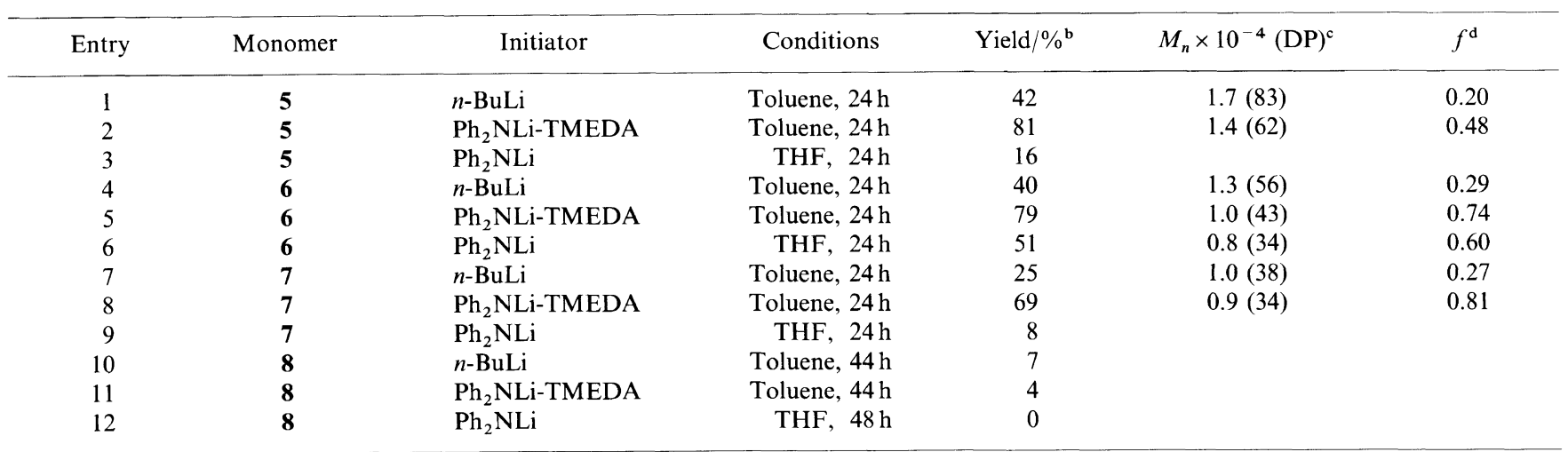

${ }^{\mathrm{a}}[$ Monomer $]=0.5 \mathrm{M},[$ Monomer $] /[$ Initiator $]=40 .{ }^{\mathrm{b}} \mathrm{MeOH}$ insoluble part. ${ }^{\mathrm{c}}$ Determined by $\mathrm{VPO}$ (solvent $\mathrm{CHCl}{ }_{3}$, benzil standard). ${ }^{\mathrm{d}}$ Efficiency of initiator. 
spectra to estimate the tacticity of the polymer was fruitless. However, H-transfer trace was hardly observed in DEPT measurement of the polymer obtained from 7 with $\mathrm{Ph}_{2} \mathrm{NLi}$-TMEDA in toluene at $-78^{\circ} \mathrm{C}$ (Table IV, entry 8). The aniline groups do not seem effective for stereocontrol of the anionic polymerization.

\section{CONCLUSIONS}

The anionic polymerization of $\alpha-(N$-substituted aminomethyl)acrylate 3 bearing a bulky amino group with lithium compounds at a low temperature afforded polymers having a normal vinyl polymer structure. A highly isotactic polymer was obtained with $n$-BuLi or the $\mathrm{Ph}_{2} \mathrm{NLi}$-TMEDA complex in toluene at $-78^{\circ} \mathrm{C}$. The obtained polymer is interest from the viewpoint of stereoregular arrangement of reactive amino groups along the polymer backbone. However, H-transfer from the reactive amino proton to the propagating chain end occurred in the anionic polymerization of the monomer 2 bearing a less bulky amino group, (1-phenylethyl)amino group. Generation of the $\mathrm{H}$-transfer units in the polymer main chain increased in the polymerization in THF and a polymer containing $43 \% \mathrm{H}$-transfer unit was obtained in the polymerization with $\mathrm{Ph}_{2} \mathrm{NLi}$ in $\mathrm{THF}$ at $-78^{\circ} \mathrm{C}$.

Acknowledgments. This work was partially supported by a Grant-in-Aid for Scientific Research (No. 11450355) from the Ministry of Education, Science, Sports and
Culture of Japan, and by CREST (Core Research for Evolutional Science and Technology) of Japan Science and Technology Corporation (JST).

\section{REFERENCES}

1. B. Yamada and S. Kobatake, Prog. Polym. Sci., 19, 1089 (1994).

2. (a) S. Habaue, H. Yamada, and Y. Okamoto, Macromolecules, 29, 3326 (1996). (b) S. Habaue, H. Yamada, T. Uno, and Y. Okamoto, J. Polym. Sci., Part A, Polym. Chem., 35, 721 (1997).

3. (a) S. Habaue, T. Uno, and Y. Okamoto, Macromolecules, 30, 3125 (1997). (b) S. Habaue, T. Uno, H. Baraki, and Y. Okamoto, Polym. J., 29, 983 (1997).

4. S. Habaue, H. Baraki, and Y. Okamoto, Polym. J., 29, 872 (1997).

5. D. S. Breslow, G. E. Hulse, and A. S. Matlack, J. Am. Chem. Soc., 79, 3760 (1957).

6. (a) S. Okamura, Y. Oishi, T. Higashimura, and T. Senoo, Koubunshi Kagaku, 19, 323 (1962). (b) H. Wexler, Makromol. Chem., 115, 262 (1968).

7. T. Tsunetsugu, T. Matsuo, and J. Furukawa, Makromol. Chem., 107, 222 (1967).

8. M. Guaita, G. Camino, and L. Trossarelli, Makromol. Chem., 131, 309 (1970)

9. S. Negishi and Y. Tamura, J. Polym. Sci., Part A-1, 5, 2911 (1967).

10. K. Kojima, N. Yoda, and C. S. Marvel, J. Polym. Sci., Part A-1, 4, 1121, (1966).

11. J. Villieras and M. Rambaud, Synthesis, 924 (1982).

12. T. Tsuruta, J. Poly. Sci., Part D, 6, 179 (1972).

13. (a) Y. Okamoto, K. Ohta, and H. Yuki, Chem. Lett., 617 (1977). (b) Y. Okamoto, K. Urakawa, K. Ohta, and H. Yuki, Macromolecules, 11, 719 (1978).

14. Y. Okamoto and E. Yashima, Prog. Polym. Sci., 15, 263 (1990).

15. T. Uno, S. Habaue, and Y. Okamoto, Chirality, 10, 711 (1998).

16. G. Wulff and Y. Wu, Makromol. Chem., 191, 3005 (1990). 